\section{OP0101-HPR QUALITY OF LIFE IN PEOPLE WITH SYSTEMIC SCLEROSIS WITH DIFFERENT DEGREES OF LUNG DISEASE - A CROSS-SECTIONAL STUDY}

C. Boström ${ }^{1,2}$, H. Pettersson ${ }^{1}$, E. Svenungsson ${ }^{1,2}$, H. Alexanderson ${ }^{1,2}$ A. Nordin ${ }^{2} .{ }^{1}$ Karolinska University Hospital, Stockholm, Sweden; ${ }^{2}$ Karolinska Institutet, Stockholm, Sweden

Background: There are few studies evaluating different aspects of quality of life including depressive symptoms and physical capacity and physical activity in patients with systemic sclerosis (SSc) with different degrees of lung disease. Objectives: The aim of this study was to evaluate differences in self-reported disability, physical capacity and activity, depressive symptoms and quality of life, between patients with SSc with no-mild lung disease and those with moderate-endstage lung disease.

Methods: In this cross-sectional study, 279 patients with SSc fulfilling the 2013 ACR/EULAR criteria for SSc (84\% limited and 16\% diffuse SSc) were included. Medsger disease severity scale was used to subgroup the patients into no-mild $(n=156)$ or moderate- endstage lung disease $(n=115)$. Disability was measured with Health Assessment Questionnaire-Disability Index (HAQ-DI); physical capacity (ability to walk, jog/run); and physical activity (different intensities) was measured with three single questions; depressive symptoms with Hospital Anxiety and Depression-scale (HADs); and quality of life was measured with The Short Form (36) Health Survey (SF-36).

Results: Patients with moderate-endstage lung disease reported higher scores on HAQ-DI $(p<0.001)$ and lower scores on SF-36 physical component $(p<0.0001)$ than patients with no-mild lung disease. Patients with moderate-endstage lung disease reported lower physical capacity $(p<0.0001)$, less physical activity on low to moderate intensity the past 6 months $(p<0.016)$ and less exercise on moderate to high intensity the past year $(p=0.022)$ compared to those with no-mild lung disease. There was no difference between the two subgroups when it comes to the mental component in SF-36 $(p=0.2)$, however patients with moderate-endstage lung disease had lower scores on the subscales vitality $((p=0.003)$, social function $(p=0.002)$ and emotional role function $(p=0.005)$ as well as higher scores on the HADs depressive symptoms scale $(p=0.024)$, than the patients with no-mild lung disease.

Conclusion: Patients with SSc with moderate-endstage lung disease report more disability, lower physical capacity and activity, are more depressed and the physical aspects of quality of life is lower, as well as vitality, social function and emotional role function, compared to patients with no-mild lung disease. Studies evaluating whether increased physical activity and exercise may improve depressive symptoms and aspects of quality of life in patients with moderate-endstage lung disease are needed.

References:

[1] Liem SIE, Meessen JMTA, Wolterbeek R, Ajmone Marsan N, Ninaber MK Vliet Vlieland TPM, de Vries-Bouwstra JK. Physical activity in patients with systemic sclerosis. Rheumatol Int. 2018;38:443-453

[2] March C, Huscher D, Preis E, Makowka A, Hoeppner J, Buttgereit F, Riemekasten G, Norman K, Siegert E. Prevalence, Risk Factors and Assessment of Depressive Symptoms in Patients With Systemic Sclerosis. Arch Rheumatol. 2019;28;34:253-261

Acknowledgments: Thanks to the patients involved in the study, patient research partner Monica Holmnér and the staff at the rheumatological clinic, Karolinska University Hospital

Disclosure of Interests: None declared

DOI: 10.1136/annrheumdis-2020-eular.5389

\section{Immunodeficiency and autoimmune disease}

\section{OP0102 GENE SCREENING OF PRIMARY IMMUNODEFICIENCY DISEASES IN PATIENTS WITH JUVENILE SYSTEMIC LUPUS ERYTHEMATOSUS}

J. LI ${ }^{1}$, W. Wang ${ }^{1}$, C. Y. Wang ${ }^{1}$, J. Y. Pan ${ }^{1}$, H. Song ${ }^{1} .{ }^{1}$ Peking Union Medical College Hospital, Peking, China

Background: Systemic lupus erythematosus (SLE) is one of the most common auto-immune diseases in childhood. Primary immunodeficiency disease (PID) patients may present or combine with autoimmune diseases.

Objectives: This study aimed to perform gene sequencing via high-throughput sequencing technology in a series of Chinese pediatric SLE patients, and investigate the concomitant situation of PIDs and SLE. Gene sequencing results may help clarify the pathogenesis of SLE.

Methods: This was a retrospective case series of SLE children who referred to the Peking Union Medical College Hospital between 01/2016 and 09/2019. Genetic tests were performed in patients who met the inclusion criteria. We then collected demographic, clinical, and treatment information of all involved patients. Descriptive statistics were used.

Results: Seventy-one patients were finally included (eighteen boys and fifty-three girls). The median age at the time of disease onset was 9.5 (range, 3-15) years. It is notable that five patients experienced their first attack before the age of five. Twenty-seven patients showed a persistent increase in ESR during treatment, while thirteen cases presented with repeated CMV infection, thirty-four cases with persistent low complement levels, seven with basal ganglia calcification showed in skull CT or MRI, four with special type of rash (i.e., frostbite-like rash, discoid erythema, reticular erythema), two with obvious hepatosplenomegaly, and one case with type I diabetes. Gene sequencing results showed that about ten patients combine with primary immunodeficiency disease, including Aicardi-Goutières Syndrome (AGS) $(n=4)$, Spondyloenchondro-dysplasia with immune dysregulation (SPENCDI) ( $n=1)$, STING-associated vasculopathy with onset in infancy $(\mathrm{SAVI})(\mathrm{n}=1)$, lysinuric protein intolerance $(\mathrm{LPI})(n=1)$, Ras-associated autoimmune leukoproliferative disorder (RALD) $(n=2)$.

Conclusion: SLE patients who present atypical or refractory manifestations should attach importance to the existence of primary immunodeficiency disease. Genetic tests are recommended for patients with early-onset SLE, especially those with recurrent frostbite-like rash or persistent CMV infection since childhood.

References:

[1] TTarr, B Dérfalvi, N Győri, et al. Similarities and differences between pediatric and adult patients with systemic lupus erythematosus[J]. Lupus. 2015, 24 796-803.

[2] Gupta S, Louis A G. Tolerance and Autoimmunity in Primary Immunodeficiency Disease: a Comprehensive Review[J]. Clinical Reviews in Allergy \& Immunology, 2013, 45(2):162-169.

Disclosure of Interests: None declared

DOI: 10.1136/annrheumdis-2020-eular.4199

\section{Spondyloarthritis - treatment}

\begin{tabular}{|l|l}
\hline OP0103 & DOES GENDER, AGE OR SUBPOPULATION \\
INFLUENCE THE MAINTENANCE OF CLINICAL \\
REMISSION IN AXIAL SPONDYLORTHRITIS \\
FOLLOWING CERTOLIZUMAB PEGOL DOSE \\
REDUCTION?
\end{tabular}

R. B. M. Landewé ${ }^{1,2}$, D. Van der Heijde ${ }^{3}$, M. Dougados ${ }^{4}$, X. Baraliakos ${ }^{5}$, F. Van den Bosch ${ }^{6}$, K. Gaffney ${ }^{7}$, L. Bauer ${ }^{8}$, B. Hoepken ${ }^{8}$, N. De Peyrecave ${ }^{9}$, K. Thomas ${ }^{10}$, L. S. Gensler ${ }^{11} .{ }^{7}$ Amsterdam Rheumatology \& Clinical Immunology Center, Amsterdam, Netherlands; ${ }^{2}$ Zuyderland Medical Center, Heerlen, Netherlands; ${ }^{3}$ Leiden University Medical Center, Leiden, Netherlands; ${ }^{4}$ Paris-Descartes University and Cochin Hospital, Paris, France; ${ }^{5}$ RuhrUniversity Bochum, Herne, Germany; ${ }^{6}$ Ghent University, VIB Center for Inflammation Research, Ghent, Belgium; ${ }^{7}$ Norfolk and Norwich University Hospital NHS Foundation Trust, Norwich, United Kingdom; ${ }^{8}$ UCB Pharma, Monheim am Rhein, Germany; ${ }^{9}$ UCB Pharma, Brussels, Belgium; ${ }^{8}$ UCB Pharma, Monheim am Rhein, Germany; ${ }^{11}$ University of California San Francisco, San Francisco, United States of America

Background: Previous studies have shown that withdrawing tumour necrosis factor inhibitors (TNFi) in patients (pts) with axial spondyloarthritis (axSpA) who have achieved sustained remission often leads to relapse. ${ }^{1}$ However, none have formally tested TNFi dose reduction strategies in a broad axSpA population or evaluated whether relapse following TNFi dose reduction and withdrawal is associated with a specific demographic subgroup.

Objectives: C-OPTIMISE evaluated the percentage of pts without flare after $\mathrm{TNFi}$ dose continuation, reduction or withdrawal in adults with early axSpA treated with the Fc-free, PEGylated TNFi certolizumab pegol (CZP). Here, we analyse whether responses to reduced maintenance dose were comparable in pts stratified by axSpA subpopulation, gender and age.

Methods: C-OPTIMISE (NCT02505542) was a multicentre, two-part phase 3b study in adults with early ( $<5$ years' symptom duration) active axSpA (stratified for radiographic [r]- and non-radiographic [nr]- axSpA). Pts received CZP $200 \mathrm{mg}$ every 2 weeks (wks) (Q2W; $400 \mathrm{mg}$ loading dose at Wks 0, 2 and 4) during the open-label induction period. At Wk 48, pts in sustained remission (Ankylosing Spondylitis Disease Activity Score [ASDAS] $<1.3$ at Wk 32 or 36 [if ASDAS $<1.3$ at Wk 32, it must be $<2.1$ at Wk 36 , or vice versa] and at Wk 48) were randomised to double-blind full maintenance dose (CZP $200 \mathrm{mg}$ Q2W); reduced maintenance dose (CZP $200 \mathrm{mg}$ every 4 wks [Q4W]) or placebo (PBO) for a further 48 wks (maintenance period). The primary endpoint was the percentage of pts not experiencing a flare (ASDAS $\geq 2.1$ at two consecutive visits or ASDAS $>3.5$ at any timepoint) during Wks 48-96. Analyses were conducted on subgroups according 
to $\operatorname{axSpA}$ subpopulation, gender and age $\leq />$ the median age of the randomised set (32 years).

Results: During the 48-wk induction period, $43.9 \%$ of patients (323/736) achieved sustained remission and 313 pts entered the 48 -wk maintenance period (r/nr-axSpA: 168/145 pts; males/females: 247/66 pts; age $\leq 32 />32: 165 / 148$ pts). During the maintenance period, responses in $\mathrm{r}$ - and $\mathrm{nr}$-axSpA pts were comparable across all three randomised arms. 83.9\% r-axSpA and $83.3 \% \mathrm{nr}$-axSpA pts receiving the full CZP maintenance dose did not experience a flare, and in the reduced maintenance dose arm $82.1 \% \mathrm{r}$-axSpA and $75.5 \% \mathrm{nr}$-axSpA pts did not experience a flare. In the PBO group this was reduced to $17.9 \%$ and $22.9 \%$, respectively. Similar responses were seen in pts stratified by gender or age, with substantially higher percentages of pts randomised to CZP full or reduced maintenance dose remaining free of flares compared to PBO in all subgroups (Figure). Conclusion: The results of C-OPTIMISE indicate that a reduced maintenance dose is suitable for pts with axSpA who achieve sustained remission following 1 year of CZP treatment, regardless of axSpA subpopulation, gender or age. Complete treatment withdrawal is not recommended due to the high risk of flare. References: [1]Landewe R. Lancet 2018;392:134-44.

Figure. Patients not experiencing flares during the maintenance period of C-OPTIMISE, stratified by: A) disease subpopulation (radiographic vs non-radiographic axSpA); B) gender (male vs female); $\mathrm{C}$ ) age ( $\leq 32$ years vs $>32$ years)
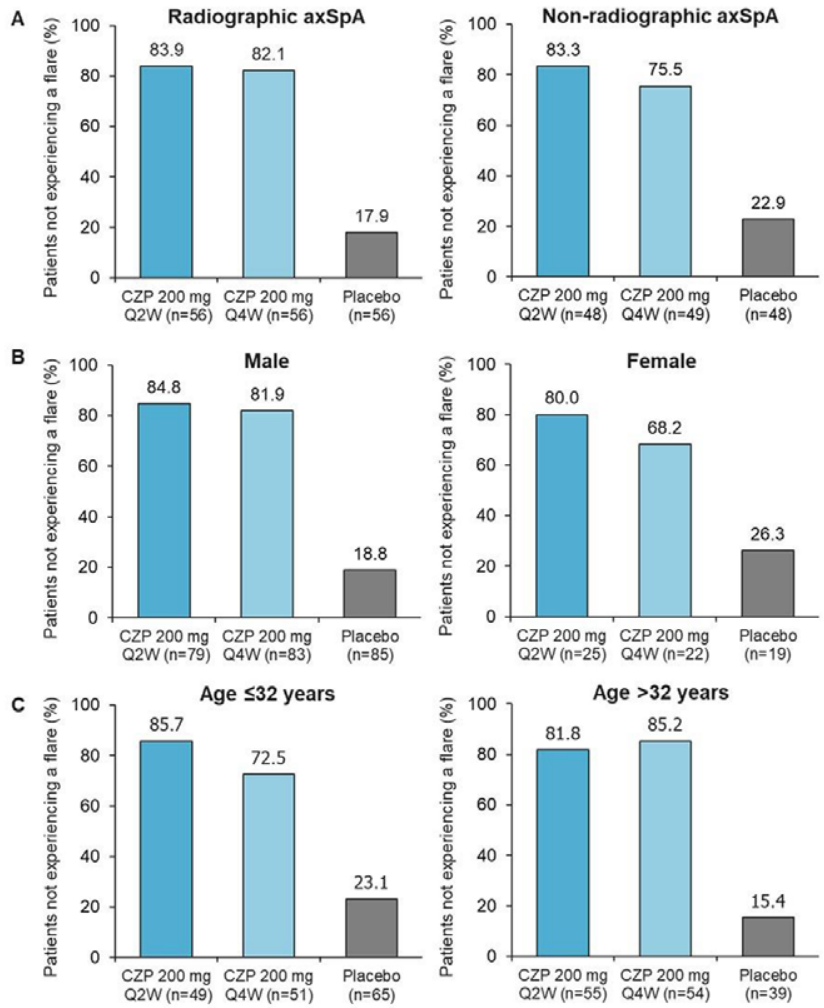

axSpA: axial spondyloarthritis; CZP: certolizumab pegol; Q2W: every 2 weeks; Q4W: every 4 weeks.

Acknowledgments: This study was funded by UCB Pharma. Editorial services were provided by Costello Medical

Disclosure of Interests: Robert B.M. Landewé Consultant of: AbbVie; AstraZeneca; Bristol-Myers Squibb; Eli Lilly \& Co.; Galapagos NV; Novartis; Pfizer; UCB Pharma, Désirée van der Heijde Consultant of: AbbVie, Amgen, Astellas, AstraZeneca, BMS, Boehringer Ingelheim, Celgene, Cyxone, Daiichi, Eisai, EliLilly, Galapagos, Gilead Sciences, Inc., Glaxo-Smith-Kline, Janssen, Merck, Novartis, Pfizer, Regeneron, Roche, Sanofi, Takeda, UCB Pharma; Director of Imaging Rheumatology BV, Maxime Dougados Grant/research support from: AbbVie, Eli Lilly, Merck, Novartis, Pfizer and UCB Pharma, Consultant of: AbbVie, Eli Lilly, Merck, Novartis, Pfizer and UCB Pharma, Speakers bureau: AbbVie, Eli Lilly, Merck, Novartis, Pfizer and UCB Pharma, Xenofon Baraliakos Grant/research support from: Grant/research support from: AbbVie, BMS, Celgene, Chugai, Merck, Novartis, Pfizer, UCB and Werfen, Consultant of: AbbVie, BMS, Celgene, Chugai, Merck, Novartis, Pfizer, UCB and Werfen, Speakers bureau: AbbVie, BMS, Celgene, Chugai, Merck, Novartis, Pfizer, UCB and Werfen, Filip van den Bosch Consultant of: AbbVie, Celgene Corporation, Eli Lilly,
Galapagos, Janssen, Novartis, Pfizer, and UCB, Speakers bureau: AbbVie, Celgene Corporation, Eli Lilly, Galapagos, Janssen, Novartis, Pfizer, and UCB, Karl Gaffney Grant/research support from: AbbVie, Celgene, MSD, Novartis Pfizer, and UCB Pharma, Consultant of: AbbVie, Celgene, MSD, Novartis, Pfizer, and UCB Pharma, Speakers bureau: AbbVie, Celgene, MSD, Novartis Pfizer, and UCB Pharma, Lars Bauer Employee of: UCB Pharma, Bengt Hoepken Employee of: UCB Pharma, Natasha de Peyrecave Employee of: UCB Pharma, Karen Thomas Employee of: UCB Pharma, Lianne S. Gensler Grant/ research support from: Pfizer, Novartis, UCB, Consultant of: AbbVie, Eli Lilly, GSK, Novartis, UCB

DOI: 10.1136/annrheumdis-2020-eular.2361

\section{\begin{tabular}{|l|l}
\hline OP0104 THE IMPACT OF PERSISTENT INFLAMMATORY \\
\hline
\end{tabular} CHANGES ON PREVALENCE OF FATTY LESIONS IN PATIENTS WITH AXIAL SPONDYLOARTHRITIS TREATED WITH CERTOLIZUMAB PEGOL: 4-YEAR MRI RESULTS FROM RAPID-AXSPA}

X. Baraliakos $^{1}$, S. Kruse ${ }^{1}$, S. Auteri ${ }^{2}$, N. De Peyrecave ${ }^{2}$, T. Nurminen ${ }^{3}$,

T. Kumke ${ }^{3}$, B. Hoepken ${ }^{3}$, J. Braun ${ }^{1} .{ }^{1}$ Rheumazentrum Ruhrgebiet Herne, RuhrUniversity Bochum, Herne, Germany; ${ }^{2}$ UCB Pharma, Brussels, Belgium; ${ }^{3}$ UCB Pharma, Monheim am Rhein, Germany

Background: Axial spondyloarthritis (axSpA) is a chronic disease characterised by inflammation in the sacroiliac joints and spine, causing severe back pain and stiffness. Emerging evidence suggests chronic spinal inflammation may be associated with osteoproliferation leading to syndesmophyte formation and spinal ankylosis, with subsequent worsening of patient mobility and function. ${ }^{1}$ Fatty lesions (FLs) on magnetic resonance imaging (MRI) $\mathrm{T} 1$ sequences are considered to be post-inflammatory precursors to these changes. Certolizumab pegol (CZP), an Fc-free, PEGylated tumour necrosis factor inhibitor (TNFi), has proven efficacy in treating the signs and symptoms of axSpA. ${ }^{2,3} \mathrm{CZP}$ has also been shown to decrease spinal and sacroiliac joint $\mathrm{MRI}$ inflammation, and limit radiographic progression of the spine over 4 years of treatment. $^{4}$

Objectives: To report the effect of early post-baseline (BL) inflammatory changes on fatty lesion prevalence over 4 years in a broad axSpA patient population treated with $\mathrm{CZP}$.

Methods: RAPID-axSpA (NCT01087762) was a phase 3 trial which was double-blind and placebo (PBO)-controlled to Week (Wk) 24, dose-blind to Wk 48 and open-label to Wk 204. CZP-randomised axSpA patients (Wk 0 CZP: $200 \mathrm{mg}$ every 2 wks [Q2W] or $400 \mathrm{mg}$ Q4W) continued their assigned dose throughout; PBO-randomised axSpA patients (Wk O PBO) received CZP from Wk 24, or if non-responders, from Wk 16 onwards. Blinded spinal MRI scans at Wks $0,12,48,96$ and 204 were assessed by 2 central readers to evaluate $F L$ and inflammatory lesions in vertebral edges (VEs). Changes in FL prevalence are reported as odds ratios (OR; FL+/FL-) between time points or inflammation states, with nominal 95\% confidence intervals $(\mathrm{Cl})$, for Wk 0 CZP. ORs were estimated from a logistic regression model for VE level data with random effects for patient and VE (within patient). The fixed model effects included time point, inflammatory status of VEs at BL and Wk 12, FL status at BL, and interactions if appropriate.

Results: Of 325 axSpA patients, 89 and 47 initially randomised to CZP or PBO respectively, had a $B L$ and $\geq 1$ post-BL $M R I$ and therefore were eligible for these analyses. In these patients, a total of 3,127 of VEs were assessed at BL; inflammation was observed in $21.6 \%$ and $F L$ in $29.3 \%$ of VEs, equating to mean counts of 5.0 and 6.7 per patient; $10.5 \%$ of VEs had both inflammation and FL at BL. At BL, FLs were relatively more often observed in inflamed VEs vs non-inflamed VEs: OR $(95 \% \mathrm{Cl})$ of $3.30(1.94,5.61)$. This difference increased over time, as the OR of FL at Wk 204 vs BL was $2.82(1.70,4.66)$ in VEs that were inflamed at $\mathrm{BL}$ compared with $1.08(0.79,1.48)$ in VEs that were not inflamed at BL (Figure $1 \mathrm{~A})$. Resolution of inflammation by $\mathrm{Wk} 12$ appeared to lower the risk of FL prevalence over 4 years. When adjusted for BL VE status with respect to inflammation and FL, if inflammation prevailed at Wk 12, the OR of FL vs no FL was $1.80(0.93,3.49)$ at Wk $48,2.54(1.32,4.91)$ at Wk 96 and $3.91(1.87,8.15)$ at Wk 204 (Figure 1B).

Conclusion: This is the first report from a clinical interventional PBO-controlled study in a broad axSpA population showing that inflammation that prevailed after the start of TNFi treatment was associated with increased FL prevalence over 4 years. Reduction of inflammation by Wk 12 mitigated the risk of FL over the long-term, indicating the importance of early, effective and long-term treatment targeting inflammation. Similarly, a complete and persistent reduction of inflammation appears to be critical in these patients.

\section{References:}

[1] Maksymowych WP. Ann Rheum Dis 2013;72:23-8; 2. Van der Heijde D. Rheumatology (Oxford) 2017;56:1498-509; 3. Deodhar A. Arthritis Rheumatol 2019;71:1101-11; 4. Van der Heijde D. Ann Rheum Dis 2018;77:699-705. 